\title{
Panel: Faculty of Practice: Female Faculty Boundary Spanners Offering \& Gaining Perspective
}

\author{
Dr. Mary K. Pilotte, Purdue University, West Lafayette
}

Mary Pilotte is Associate Professor of Engineering Practice in the School of Engineering Education at Purdue University, West Lafayette, Indiana. She leads the First-Year Engineering instructional operations group, is an instructor for First-Year Engineering and Multidisciplinary coursework, and was recently appointed Director Designate for the undergraduate Interdisciplinary Engineering Studies and Multidisciplinary Engineering program. With over 20 years of industrial work experience, and supportive of her academic roles, Mary actively leads academic outreach to industrial firms to develop in-classroom, project-based, active learning through identification of "real life", in-context problem scenarios.

Pilotte's research interests involve understanding engineering culture, identity, and communication in the context of professional engineering practice. Expanded interests include understanding student benefits associated with in-context active learning, innovative distance learning, and global learning experiences. She holds Bachelor of Science degree in Organizational Leadership and Supervision from Purdue University, an MBA from the Goizueta School of Business, Emory University, Atlanta, Georgia, and a Ph.D. in Engineering Education from Purdue University.

\section{Dr. Diana Bairaktarova, The University of Oklahoma}

Diana Bairaktarova is an Assistant Professor of Engineering Practice in the College of Engineering, School of Aerospace and Mechanical Engineering at University of Oklahoma. Diana has over a decade of experience working as a Design Engineer. Her research is focused on human learning and engineering, i.e. understanding how individual differences and aptitudes affect interaction with mechanical objects, and how engineering students' personality traits influence ethical decision-making process in engineering design.

\section{Rachel Louis Kajfez, Ohio State University}

Dr. Rachel Louis Kajfez is an Assistant Professor of Practice in the Engineering Education Innovation Center and the Department of Civil, Environmental, and Geodetic Engineering at The Ohio State University. She earned her B.S. and M.S. degrees in Civil Engineering from Ohio State where she specialized in construction and researched sustainable bridge practices for her masters' thesis. She earned her Ph.D. in Engineering Education from Virginia Tech in 2013 where she studied the motivation and identity of graduate teaching assistants in first-year engineering programs. Additionally at Virginia Tech, Rachel was a Dean's Teaching Fellow, which afforded her the opportunity to teach first-year engineering courses along with graduate level teaching practicums. Her current research interests focus on the intersection between motivation and identity of undergraduate and graduate students, first-year engineering programs, mixed methods research, and innovative approaches to teaching. She is a recipient of the 2012 American Society for Engineering Education Women in Engineering Division Mara H. Washburn Early Engineering Educator Grant. Currently, she teaches within the first-year engineering program at Ohio State while maintaining an active engineering education research program. 


\title{
Faculty of Practice: Female Faculty Boundary Spanners Offering \& Gaining Perspective
}

\begin{abstract}
Universities seem to be reviving their interest in engaging industrial concerns and newly specialized fields of study. Among engineering schools, there is an increased dialogue around the desire for greater connections with industry with the goal of seeking richer understanding of actual engineering practice. In the classroom, pedagogies of engagement and active learning often demand "in context" learning scenarios to provide students with authentic engineering experiences guided by those experienced in education. This quest for collaboration and authenticity is also seen in calls for funding proposals, which often encourage some explicit form of participation by industrial firms or practitioners along with those versed in very specific fields. But what is the model for cultivating and sustaining such connections and for hiring those who may meet a niche need?
\end{abstract}

One approach taken to forge related connections and to acquire those in targeted fields is the hiring of academically credentialed and often industry experienced engineers back into the university as faculty. Sometimes referred to as faculty of practice (FOP), these individuals offer the benefit of extensive "real life" experience either in industry or their specialized area, while carrying the credibility that accompanies having survived the rigors of a technically oriented, and or research-based Ph.D. In addition, FOP often come with rich personal connections and external contacts that would take years to develop organically from inside an academic institution.

This panel will engage a variety of "boundary spanning" faculty from a range of institutions for a lively panel discussion surrounding topics such as: common attributes and assignments associated with the FOP role; professional decisions around joining the academic community; first impressions and experiences in the FOP role; opportunities and benefits to nonFOP faculty colleagues and institutions; considerations for FOP as a career pathway; and lessons learned/advice for individuals and institutions considering FOP faculty roles, to name a few. An open question and answer session will follow.

Key words: industrial engagement, industry, gender, female faculty, engineering faculty of practice, career transformation, faculty of professional practice, boundary spanning, academic career opportunity. 